\title{
ПРОБЛЕМЫ ПРАВОВОГО РЕГУЛИРОВАНИЯ ОТНОШЕНИЙ В УСЛОВИЯХ ДЕЙСТВИЯ COVID-2019
}

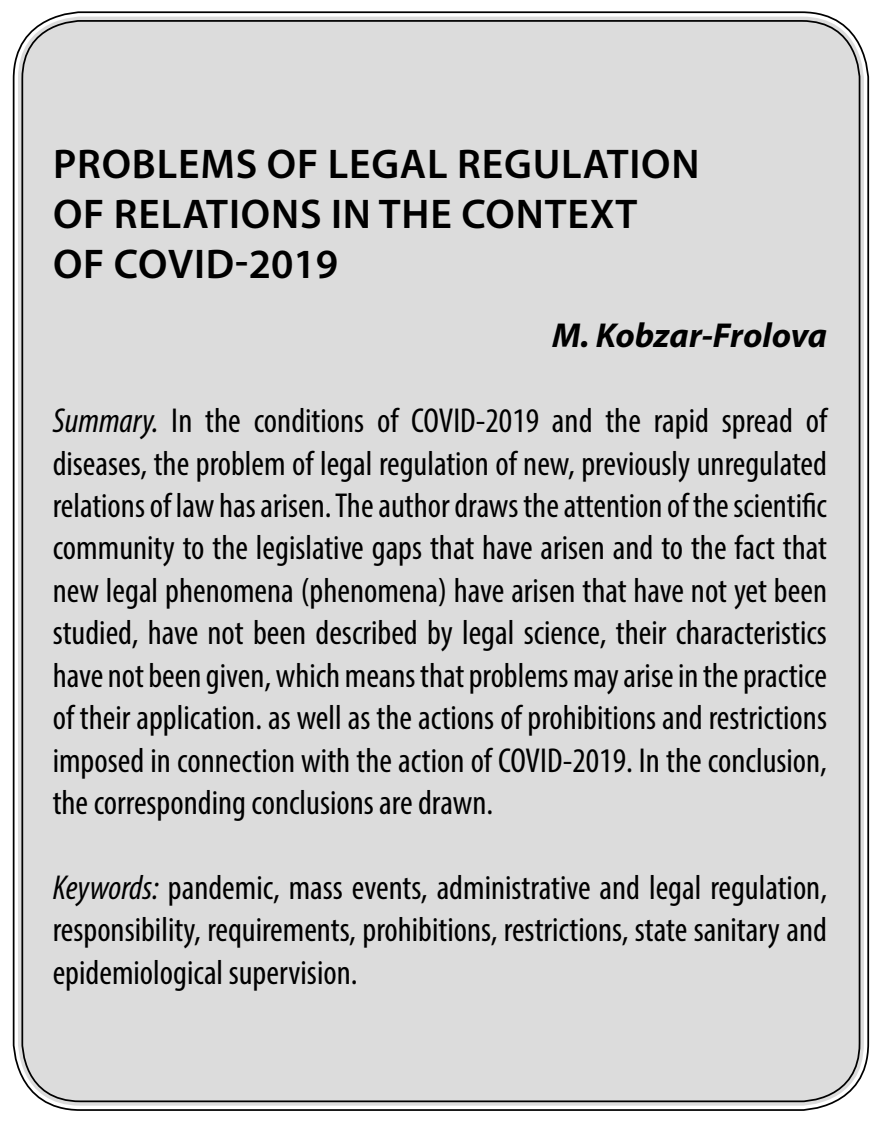

B озникновение и стремительное распространение ранее неизвестного заболевания, связанного с действием COVID-2019, стало потрясением для стран всего мира. Уже больше года большинство стран мира вынуждены жить в условиях пандемии. Последствия действия пандемии еще долго будут изучать ученые всего мира. Но до настоящего времени многие страны вынуждены прекратить или ограничить международные связи (торговлю, перевозки, туризм и многое иное), поскольку связь с внешним миром приводит к новым штаммам и угрозам жизни, здоровью, наносит вред экономике. Люди устали от введения запретов и ограничений.

При этом, любое явление жизни, даже негативное, порождает некий круг общественных отношений и их участников. Впрочем, всякий общественный процесс приводит к развитию, в отдельных случаях к деградации. Действие пандемии, тоже не могло не остаться вне рамок исследования юридической науки. Все те аспекты социальной жизни, на которые влияет распространение
Кобзарь-Фролова Маргарита Николаевна

Д.ю.н., профессор, г.н.с., Институт государства и права Российской академии наук, г. Москва MargoKFMN@yandex.ru

Аннотация. В условиях действия COVID-2019 и стремительного распространения заболеваний, возникла проблема правового регулирования новых, ранее неурегулированных нормами права отношений. Автор обращает внимание научной общественности на возникшие законодательные пробелы и на то обстоятельство, что возникли новые правовые явления (феномены), которые до настоящего времени не изучены, не описаны юридической наукой, не даны их характеристики, а значит могут возникать проблемы в практике их применения, а также действия запретов и ограничений, вводимых в связи с действием COVID-2019. В заключении делаются соответствующие выводы.

Ключевые слова: пандемия, массовые мероприятия, административно-правовое регулирование, ответственность, требования, запреты, ограничения, государственный санитарно-эпидемиологический надзор.

COVID-2019 должны быть подвергнуты научному анализу, синтезу, обобщению и систематизации.

Задача любой науки описать возникшее общественное отношение, выделить его характерные признаки, дать характеристики субъектам, представить общественности дефиниции, категории, показать общественные связи, роль и влияние на иные, связанные отношения. Для юридической науки главная цель - снабдить юриста, прежде всего правоприменителя, судью, уполномоченных должностных лиц, толкованием норм позитивного права страны. Не менее важным - дать законодателю предложения о включении в нормативные акты описанного феномена и при необходимости установить обязательные требования, запреты, ограничения, связанные с его действием и влиянием на общественную жизнь людей. Особенно юридическая наука должна живо реагировать в тех условиях, когда отсутствие знаний может негативным образом отразится на безопасности граждан и создавать угрозу их жизни, здоровью, здоровью будущего поколения, правам и свободам. 
C распространением коронавирусной инфекции в общественный оборот вошли термины, которые не использовались ранее правоприменителем не были отражены в нормативных правовых актах не только России, но и многих странах мира. Аналитики компании «Яндекс» составили рейтинг новых и наиболее популярных слов, основанных на данных поисковых запросов по аналогии с британскими лингвистами, которых тоже занимали вопросы наиболее рейтинговых, самых употребляемых слов и выражений уходящего года. К ним были отнесены: «пандемия», «локдаун» или изоляция, (резкое сокращение социальной активности по причине закрытия учреждений и запретов на передвижение), а также «самоизоляция», «удалёнка», «эпидемия», «ограничительные меры» $[13,14]$. Однако в общественный оборот вошли не только эти, но и иные новые имеющие социальное значение термины, например, такие как: «массовые мероприятия», «места скопления людей (граждан)», социальное дистанцирование, соблюдение (несоблюдение) социальной дистанции», «масочный режим», «использование средств коллективной и индивидуальной защиты». Введение превентивных мер породило вхождение в социальных оборот словосочетаний, как «ответственность за неношение масок и перчаток в общественных местах», а также запрет собираться с группами лиц и другие, а также ограничения, связанные с режимом действия того, что понимается под указанными терминами. При этом можно констатировать, что указанные термины не в полной мере отражены в российском законодательстве и слабо раскрыты юридической наукой $[9$, с. $4 ; 10$, с. 74$]$.

Всемирной организацией здравоохранения зафиксирован факт, что в ноябре 2020 года каждые 17 секунд в Европе умирает от COVID-19 один человек. 2020 год вообще останется в мировой истории как год, когда свирепствовала пандемия коронавируса и мировое сообщество в целом и правительство каждой страны вынуждено направить усилия на предотвращение опасности массовых заболеваний и снижения нагрузки на учреждения здравоохранения [13].

Граждане стран, где свирепствует пандемия, в том числе граждане России и лица, находящиеся на территории России, обязаны выполнять требования санитарного законодательства страны, а также постановления, предписания должностных лиц, осуществляющих федеральный государственного санитарно-эпидемиологического надзора [8, с.13-14]. Это правило установлено статьей 10 Федерального закона от 30.03.1999 № 52-Ф3 (ред. от 13.07.2020) «О санитарно-эпидемиологическом благополучии населения» [4].

Любой запрет, ограничение - это действие административно-принудительных мер. А значит описать их и дать предложения правоприменителю - задача, прежде всего, для ученых административистов. К сожалению, как часто это бывает, законодатель вынужден идти на опережение и срочным образом регулировать возникшие, ранее неурегулированные отношения, а наука вынуждена «догонять» законотворчекую идею, воплощенную в норму, описать, выявить пробелы, коллизии, иные недостатки.

Как известно, устанавливать запреты, вводить ограничения, обязательные требования могут как субъекты на уровне федерации, так и на уровне ее субъектов, а в отдельных случаях органы местного самоуправления.

Мэром Москвы был издан Указ от 05.03.2020 № 12-УМ (ред. от 06.10.2020) «О введении режима повышенной готовности» [6] в связи с угрозой распространения в городе Москве новой коронавирусной инфекции (2019-CoV). Одновременно было подготовлено Письмо Департамента здравоохранения г. Москвы от 30.03.2020 № 1018-161/20 «Об ограничениях передвижения по городу, установленных указом Мэра Москвы от 5 марта 2020 г. № 12-УМ «О введении режима повышенной готовности» [6]. Указ соответствует требованиям пункта 6 статьи 4.1 Федерального закона от 21 декабря 1994 г. № 68-Ф3 (в ред.08.12.2020) «О защите населения и территорий от чрезвычайных ситуаций природного и техногенного характера» [5]. Мэр Москвы постановил:

- ввести на территории г. Москвы режим повышенной готовности;

- запретить проведение на территории г. Москвы спортивных, зрелищных, публичных и иных массовых мероприятий;

- временно приостановить проведение досуговых, развлекательных, зрелищных, культурных, физкультурных, спортивных, выставочных, просветительских, рекламных и иных подобных мероприятий с очным присутствием граждан, а также оказание соответствующих услуг, в местах массового посещения граждан.

Нельзя не обратить внимание на то, что своим Указом, Мер Москвы вводит такие термины как: «массовые мероприятия», «мероприятия с очным присутствием граждан», «места массового посещения граждан». Возникает вопрос: какие мероприятия признаются массовыми? Массовое - это сколько человек конкретно? Хотелось бы получить разъяснения по каждому из введенных терминов.

Ежедневно новостные ленты сообщают об ограничениях, вводимых за рубежом, и они постоянно меняются, как правило, в сторону более жестких мер. Например, в Британии, Германии, Франции и некоторых других европейских государствах не рекомендуется 
собираться группами 6-10 чел. За нарушение этого правила установлена ответственность, вплоть до лишения свободы. Так, в Италии для граждан, получивших предписание без специального разрешения не выходить на улицу и не покидать города, закрытые на карантин, предусмотрено наказание в виде лишения свободы на срок до трех месяцев или штраф до €206. В Испании за несоблюдение приказов, запретов, инструкций или запросов, сделанных компетентными органами во время чрезвычайного положения, предусмотрены штрафы от $€ 1,5$ тыс. до $€ 600$ тыс. В Израиле за нарушение карантина по небрежности грозит лишение свободы до трех лет, если карантин нарушен намеренно - до семи лет [15]. В России пока такие правила не вводились. Но тем не менее, группа 6-10 чел.- это массовое мероприятие?

Всемирная организация здравоохранения (далее ВОЗ) выпустила 29.05.2020 «Основные рекомендации по планированию массовых мероприятий в контексте COVID-19» [12]. Россия не только участник ВО3, но и с 15 июля 2007 года стала участником Международных медико-санитарных правил [12]. Целью данного документа является предоставить руководящие указания правительствам, органам здравоохранения и другим по сдерживанию рисков передачи COVID-19, связанных с массовыми мероприятиями, массовыми собраниями $[10$, с. 75,75; 11, с. 18-23]. ВОЗ в этой связи вводит дефиницию «массовые мероприятия» - это мероприятия, характеризующиеся концентрацией людей в определенном месте для определенной цели в течение определенного периода времени, которые могут привести к нагрузке на ресурсы планирования и реагирования. Массовые мероприятия могут включать одно мероприятие или сочетание нескольких событий в разных местах, таких как Олимпийские игры. И перечисляет виды (разнообразие) массовых мероприятий: спортивные, музыкальные/развлекательные, религиозные, крупные конференции, выставки, и др. В контексте COVID-19 массовые мероприятия - это события, которые могут усилить передачу вируса и потенциально подорвать способность органов реагирования. В моем представлении данное определение не сняло поставленного вопроса. Таким образом, собравшиеся в кафе, пабе граждане, которые пришли туда каждый сам по себе - не массовое мероприятие. Пусть общаются, заражают друг друга и распространяют заболевание. Офис, собрание коллектива на совещание - вообще выпадает из этого определения. Да и многие другие (поход, религиозные, культовые мероприятия и др.).

Из смысла рекомендаций ВОЗ можно сделать вывод о том, что массовые мероприятия могут быть запланированными или спонтанными. Спонтанные мероприятия должны быть сведены к минимуму, поскольку эти события, не имеющие надлежащего планирования для осуществления мер профилактики и контроля за снижением риска, несут потенциальную нагрузку на службы здравоохранения.

Между тем, ВОЗ дает характеристики массового развлекательного мероприятия: 1) они имеют важные последствия для психологического благополучия большого людей; 2) имеют существенные политические, культурные, социальные и экономические последствия; 3) в них вовлекается большое число людей; 4) имеют важное значение для общества 5) проведение этого мероприятия необходимо (нужно) обществу. Значит в кафе, на горнолыжный курорт - можно.

Еще ВО3 рекомендует условия, которые должны быть соблюдены при проведении массовых мероприятий: риски для здоровья населения должны быть минимизированы; приняты меры планирования мероприятия; обеспечено соблюдение всех правил и обязательных требований и др.

Между тем, российский законодатель на федеральном уровне пока никаким образом не отразил в нормах права рассматриваемые понятия. При этом несоблюдение установленных требований, запретов и ограничений, обеспечивается мерами государственного принуждения, подпадающими под санкции Главы 6 Кодекса Российской Федерации об административных правонарушениях (далее - КоАП РФ). Более того, законодатель усилил меры ответственности за их несоблюдение. Так, например, по состоянию на ноябрь 2020 г установлена административная ответственность за нарушение санитарно - эпидемиологических правил, за правонарушения посягающие на здоровье, санитарно-эпидемиологическое благополучие населения. В частности, действия (бездействие) связанные с нарушением законодательства в области его обеспечения, выразившееся в нарушении действующих санитарных правил, их невыполнении и нарушении противоэпидемических мероприятий, совершенных в период режима чрезвычайной ситуации или при возникновении угрозы распространения заболевания, представляющего опасность для окружающих, в период действия карантина, либо невыполнение предписания (постановления) или требования органа (должностного лица), осуществляющего федеральный государственный санитарный эпидемиологический надзор (например, статья 6.3 КоАП РФ, с внесенными в нее изменениями в апреле 2020 года). Статья 20.2.2. КоАП РФ устанавливает ответственность за организацию 1) массового одновременного пребывания и (или) 2) передвижения граждан в общественных местах, 3) повлекших нарушение общественного порядка.

Еще один законодательный пробел состоит в том, что понятие «общественный порядок» также не определе- 
но нормативно. До настоящего времени идут дискуссии в отношении его сути и содержания.

Гипотезой статьи 20.2.2. КоАП РФ [2] является то, что ответственности подлежит организатор, если он инициирует массовое одновременное пребывание и (или) передвижение граждан в общественных местах и мероприятие не относится к публичным мероприятиям, то есть действия организатора не квалифицируются как нарушение норм Федерального закона от 19 июня 2004 года № 54-Ф3 «О собраниях, митингах, демонстрациях, шествиях и пикетированиях» [5]. Но в таком случае, владелец кафе, магазина, курорта не является организатором мероприятия и не может быть привлечен к ответственности. Это его бизнес, средство существования его, его семьи и работников. Он создал площадку для досуга и не более. При этом он обязан обеспечить соблюдение правил ведения бизнеса в рассматриваемых условиях.

К сожалению, еще больше неопределенности внес Конституционный Суд Российской Федерации, который в своем Определении от 24.10.2013 № 1721-О по этому вопросу выразил позицию, что понятие «массовое одновременное пребывание или передвижение в общественных местах» образуют общественные отношения, на которые распространяется действие, и к данной категории относятся не любые проводимые в общественных местах мероприятия, а лишь такие массовые мероприятия, которые преследуют заранее определенную цель, характеризуются единылм замыслом их участников и свободным доступом граждан к участию в них, но не являются публичными мероприятиями по смыслу Федерального закона от 19 июня 2004 года № 54-Ф3
«О собраниях, митингах, демонстрациях, шествиях и пикетирования» [5]. Если опираться на Определение Конституционного Суда, то проводимые, например, научные конференции, не могут быть признаны массовым мероприятием. На конференцию участники регистрируются, могут пройти в помещение только по предъявлению документа и с соблюдением требований организатора...

Таким образом, вопросы о том, какие мероприятия признаются массовыми, массовое - это сколько человек конкретно, остаются открытыми и требуют разъяснений и законодательного закрепления. В Институте государства и права Российской академии наук ведутся исследования в данном направлении на уровне кандидатской диссертации. При этом предлагается ввести в социальный и научный оборот такие термины, как «мероприятие с ограниченным количеством участников», которое будет имманентно и производно от понятия массовое мероприятие, а также «группа участников» имманентное термину «мероприятие с ограниченным количеством участников» и обосновать их значение с учетом законодательных требований и ограничений. Представляется, что количественное обоснование массового мероприятия должно быть передано на местный уровень, исполнительным органам местного самоуправления. Поскольку густонаселенность территорий разная, разный уровень обеспеченности медицинскими учреждениями и др. Насколько власти на местах могут обеспечить степень защиты, равно как и снизить риск неблагоприятных последствий от проведения массового мероприятия на разных территориях они должны решать самостоятельно, учитывая рекомендации ВОЗ и федерального законодательства.

\section{ЛИТЕРАТУРА}

1. Всемирная организация здравоохранения «Основные рекомендации по планированию массовых мероприятий в контексте COVID-19»/https:// rospotrebnadzor.ru/ по состоянию на 08.06.2020.

2. Кодекс Российской Федерации об административных правонарушениях.

3. Федеральный закон от 21 декабря 1994 г. № 68-Ф3 «0 защите населения и территорий от чрезвычайных ситуаций природного и техногенного характера»/

4. Федеральный закон от 30.03.1999 № 52-Ф3 (ред. от 13.07.2020) «0 санитарно-эпидемиологическом благополучии населения»// Собрание законодательства РФ, 05.04.1999, № 14, ст. 1650

5. Федеральный закон от 19 июня 2004 года № 54-Ф3 «0 собраниях, митингах, демонстрациях, шествиях и пикетированиях»/ Собрание законодательства $P Ф, 21.06 .2004$, № 25, ст. 2485.

6. Указ Мэра Москвы от 05.03.2020 № 12-УМ (ред. от 06.10.2020) «0 введении режима повышенной готовности»/ официальный портал Мэра и Правительства Москвы http://www.mos.ru, 05.03.2020

7. Письмо Департамента здравоохранения г. Москвы от 30.03.2020 № 10-18-161/20 «06 ограничениях передвижения по городу, установленных указом Мэра Москвы от 5 марта 2020 г. № 12-уМ «0 введении режима повышенной готовности» / Документ опубликован не был// Режим доступа СПС КонсультантПлюс

8. Редкоус В.М. Административно-правовое обеспечение национальной безопасности в государствах — участниках Содружества Независимых Государств: автореф. дисс. ... докт. юр. наук. М., 2011 С. 13-14.

9. Аносов И.С. Формирование системы взаимодействия субъектов обращения лекарственных средств на основе концепции фармацевтической безопасности: автореф. дисс. ... канд. фарм. наук. М. 2016 С. 4

10. Литовкина М.И. Российское законодательство в области обеспечения лекарственной безопасности // Ученые записки № 6, Том 2, 2013 С. 74-76/ 
11. Беликова А.В., Комаров М.П. Категория «социальная безопасность» и ее место в системе национальной безопасности // Научно-технические ведомости Санкт-Петербургского государственного политехнического университета./ Гуманитарные и общественные науки. 2015 № 1 (215). С. $18-23$.

12. Официальный сайт Всемирной организации здравоохранения https://www.who.int/ihr/legal_issues/states_parties/ru/

13. Официальный сайт Российской газеты: https://rg.ru/2020/11/24/voz-kazhdye-17-sekund-v-evrope-ot-koronavirusa-umiraet-odin-chelovek.html/o6paщeние от 03.12.2020

14. https://yandex.com/news/instory/YAndeks_sostavil_top_novykh_slov_desyatiletiya-a465a6de2438e0de790d4c0751ac7b69?persistent_id=2176/ дата 0бращения 25.11.2020

15. Официальный сайт TACС России https://tass.ru/info/7989649// дата обращения 03.12.2020

\footnotetext{
( ) Кобзарь-Фролова Маргарита Николаевна ( MargoKFMN@yandex.ru ).

Журнал «Современная наука: актуальные проблемы теории и практики»
}

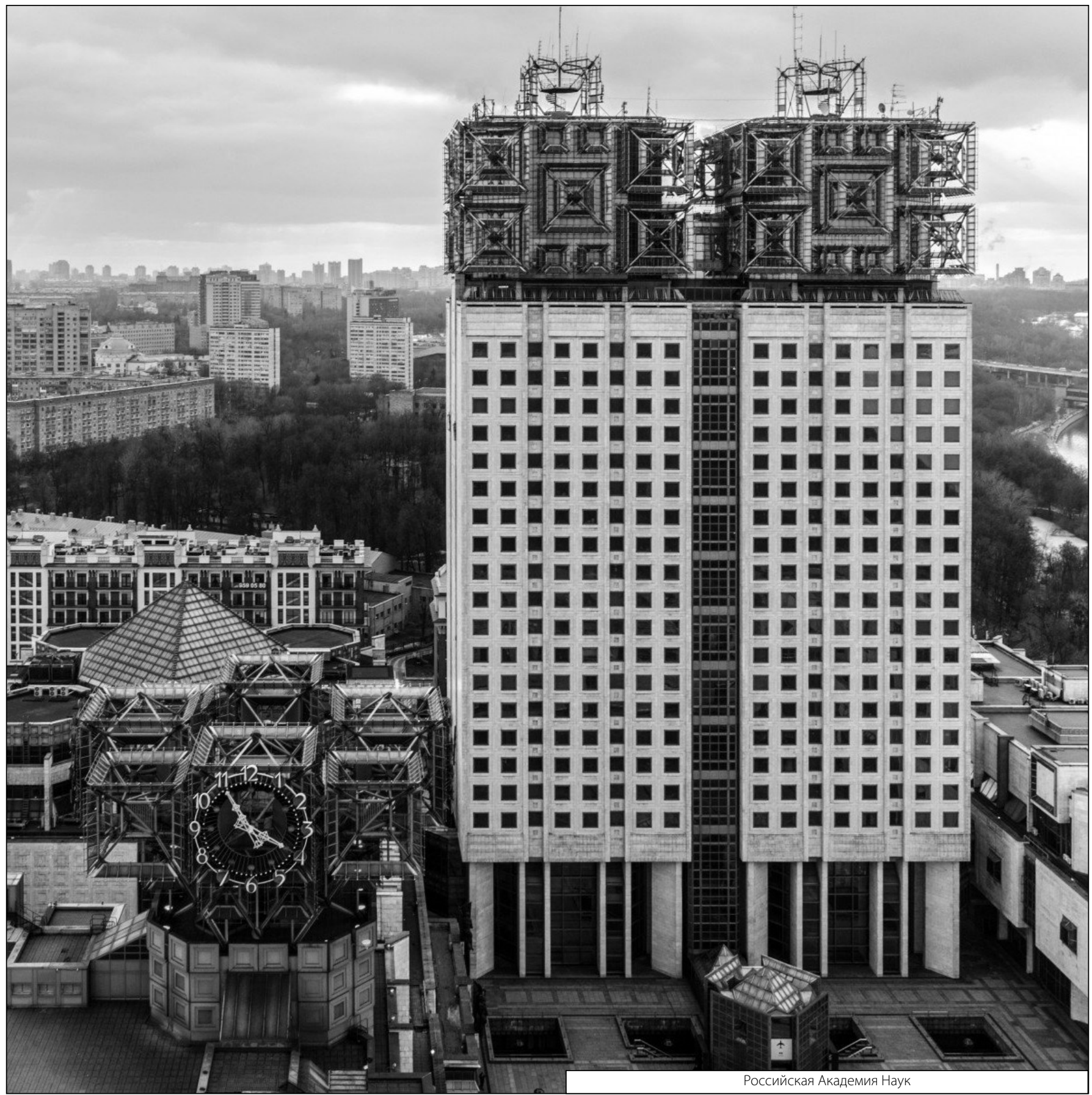

